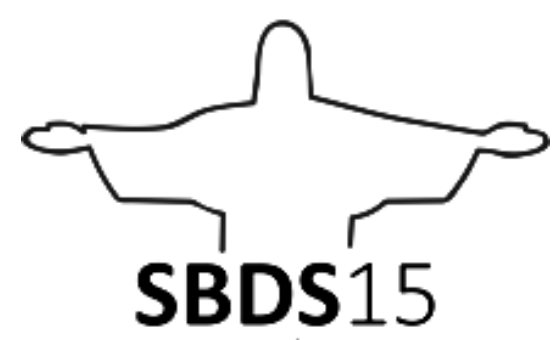

5 SIMPÓSIO DE DESIGN SUSTENTAVEL

Rio de Janeiro, 11 de novembro a 13 de novembro de 2015

\title{
DESIGN E ARTESANATO NO BRASIL: reflexões sobre modelos de atuação do design junto a grupos de produção artesanal
}

\author{
Elisa Feltran Serafim \\ eli.fserafim@gmail.com \\ Prof. Dr. Virginia Cavalcanti \\ Universidade Federal de Pernambuco/ UFPE \\ cavalcanti.virginia@gmail.com \\ Prof. Dr. Dulce Maria Paiva Fernandes \\ Universidade Federal do Paraná / UFPR \\ dulcemaria.paivafernandes@gmail.com
}

\begin{abstract}
Resumo: $O$ presente artigo apresenta os resultados de uma pesquisa ${ }^{1}$ baseada na interação entre o design e o artesanato brasileiro a partir do século XXI. Na busca pelo reconhecimento dessa interação e diferentes formas de atuação que podem ocorrer, foram analisados seis modelos de relacionamento entre designers e artesãos, sendo dois modelos quando os designers atuam em núcleos de extensão universitária/acadêmica, dois em associações sem fins lucrativos e dois como profissionais autônomos, que junto a grupos produtivos desenvolvem, por meio de diferentes métodos, ações com significativos impactos sociais, ambientais e econômicos. A partir das similaridades e divergências entre esses formatos é possível observar e realizar análises que permitem orientar pesquisas, projetos e novas políticas públicas buscando o constante aprimoramento desta atuação.
\end{abstract}

Palavras-chave: design e artesanato, modelos de atuação, grupos produtivos.

\footnotetext{
${ }^{1}$ Pesquisa de mestrado realizada junto a Universidade Federal de Pernambuco concluída em 2015:

“Design e Artesanato: análises de modelos de atuação de design junto a grupos de produção artesanal”.
} 


\begin{abstract}
The present article shows the results of a research ${ }^{2}$ based on the interaction between design and Brazilian handcrafts from the 21th century. In order to have a recognition of this interaction and the different forms it can occur, six models of relationship among designers and handcrafters were analysed: two of them were performed by university extension centers, two by non-profit organizations and the other two by autonomous professionals. When these models interact with productive groups, they develop in many different methods actions what result in social, environmental and economical impacts. From the similarities and differences between these formats, the improvement of the interaction between design and handcraft is notorious. This perception allows the approach of new researches, projects and new public politics.
\end{abstract}

Keywords: design and handcrafts, models of relationship, productive groups.

\title{
1. INTRODUÇÃO
}

Desde os anos 2000 é observado um aumento constante do número de ações de design junto a grupos de produção artesanal. Neste recente cenário, diferentes modelos de atuação começam a surgir através de projetos relacionados a atividades de extensão acadêmica, ONGs (Organizações Não Governamentais) e profissionais autônomos. Temáticas como sustentabilidade e economia solidária impulsionam diferentes processos de atuação de design junto ao artesanato promovendo a criação de diferentes materiais, produtos, serviços e processos de gestão e de produção.

Nesse contexto o designer é um importante agente que atua como mediador e facilitador de processos no desenvolvimento de ações junto a grupos e comunidades de artesãos.

Devido à relação histórica do design com o processo de produção industrial, as atividades promovidas pelo designer junto ao artesanato ainda são desenvolvidas de maneira bastante intuitiva, visto que as instituições de ensino de design ainda hoje mantêm rígidos padrões em seus métodos de ensino voltados quase que exclusivamente à produção industrial.

A história do artesanato está diretamente relacionada com o processo de adaptação do ser humano à natureza. Os primeiros artefatos criados pelo ser humano que interferem no espaço natural dão início à manifestação da cultura material. Esses artefatos geram comunicação e passam a fazer parte das relações sociais entre os indivíduos. O ser humano, por meio da sua atividade de criação e produção, vem continuamente modificando seu ambiente natural. $O$ artesanato é a prática de conformação de artefatos por meio do fazer manual.

O design, associado à revolução industrial e a diferentes formas de produção através do uso da máquina resultando em grandes quantidades de objetos seriados, representa um outro contexto de criação e desenvolvimento de objetos.

Orientado pela dicotomia e ao mesmo tempo pelos paradoxos desses dois universos o objetivo geral desse artigo é apresentar algumas análises e seus resultados

\footnotetext{
${ }^{2}$ Master's research Federal University of Pernambuco completed in 2015: "Design and Crafts: design performance model's analysis along handicraft production groups."
} 
de um estudo de múltiplos casos sobre diferentes modelos de atuação do design junto a grupos de produtivos.

Segundo Yin (2001), no estudo de casos múltiplos "cada caso em particular consiste em um estudo completo, no qual se procuram provas convergentes com respeito aos fatos e às conclusões para o caso" (YIN, 2001, p. 72). Em busca de resultados que sejam abrangentes, é possível realizar diferentes análises que permitam uma investigação sob uma lógica de replicação.

A partir de um mapeamento pré-estruturado sobre ações e projetos de design relacionados ao artesanato os casos selecionados foram:

a) Laboratório de Design Solidário - LabSol - um laboratório de extensão e pesquisa do Departamento de Design da Faculdade de Arquitetura, Artes e Comunicação (FAAC) da Universidade Estadual de São Paulo - UNESP - campus Bauru. Localizado junto ao departamento de Design, o laboratório começou a atuar em 2007 com comunidades que tinham como base de subsistência a produção artesanal. A proposta central dos projetos desenvolvidos pelo laboratório é a promoção de ações conjuntas entre o design e o artesanato estimulando a troca de saberes acadêmicos e populares, visando não apenas a qualificação do produto, e sua inserção no mercado, como também a preservação e a conscientização ambiental unidas à economia solidária, os principais objetivos da atuação do Laboratório.

b) Laboratório O Imaginário - um laboratório voltado à pesquisa e extensão acadêmica em Design da Universidade Federal de Pernambuco (UFPE) que atua com demandas relacionadas às produções artesanal e industrial desde 2001. O Laboratório está localizado junto ao Centro Cultural Benfica que reúne também o Instituto de Arte Contemporânea e o Teatro Joaquim Cardozo vinculados à UFPE. De caráter multidisciplinar, o Laboratório visa articular e fortalecer o contato da Universidade junto a ações que aproximem o design do artesanato e de empresas.

c) Design Possível - iniciou suas ações em 2004 primeiramente como uma experiência acadêmica no curso de Design em um projeto de extensão pela Universidade Presbiteriana Mackenzie em São Paulo. O projeto começou com uma parceria junto a Università degli Studi di Firenze (Itália) com o foco na experimentação e aplicação de pesquisas acadêmicas junto ao terceiro setor (ONGs das regiões periféricas de São Paulo). Com a experiência adquirida nesses anos de atuação, o projeto sintetizou suas atividades e desenvolveu um modelo focado em grupos de produção artesanal com o objetivo de "promover seu desenvolvimento e emancipá-los como grupos independentes e sustentáveis economicamente" (DESIGN POSSÍVEL, 2012). Em 2009, o Design Possível se tornou juridicamente uma associação e passou a atuar profissionalmente no terceiro setor. Desvinculando-se aos poucos do projeto de extensão.

d) Centro Pernambucano de Design (CPD) - iniciou suas ações a partir de 2004 com auxílio da proposta do Programa Brasileiro 
de Design (PBD) que estimulou a criação de Centros e Núcleos de Design no Brasil. Através desse programa o projeto foi incubado pelo SEBRAE Pernambuco e, depois de um ano de experiência adquirida, em 2005, se consolidou juridicamente como associação tendo como sócios fundadores 11 instituições, sendo uma delas o SEBRAE-PE. O Centro Pernambucano de Design promove e articula atividades de design em âmbito estadual e regional prestando atendimento às micro, pequenas e médias empresas que necessitam de apoio e inovação em design. Artesãos, grupos de produção artesanal e empreendedores em fase de abertura de um novo negócio também são orientados pela associação.

e) Paula Dib designer de produto pela FAAP, São Paulo, atua com grupos de produção artesanal desde os anos 2001. Com experiências em projetos com grupos produtivos nacionais e internacionais além de consultora é também proponente a partir de editais de fomento. Como o foco em atividades de longa duração (1 a 2 anos) ela acompanha passo a passo os processos e técnicas artesanais com intuito de resgatar e revalorizar os saberes das culturas locais.

f) Sérgio Matos designer de produto pela Universidade Federal de Campina Grande (UFCG) na Paraíba, desde 2008, atua com o desenvolvimento de produtos utilizando como processo produtivo a prática artesanal. A partir de 2012 começou a atuar como consultor de design em grupos de produção artesanal e desde então trabalha em diferentes regiões do Brasil buscando estimular a produção artesanal como forma de desenvolvimento local e geração de renda.

Tomando-se como foco o histórico das atuações, as estruturas de cada um desses modelos e a motivação em realizar uma reflexão sobre os impactos e as perspectivas da relação entre o design e o artesanato a partir dos anos 2000, buscouse compreender como estes diferentes modelos se configuram para o desenvolvimento e a execução de ações junto aos grupos de produção artesanal, quais as suas similaridades e divergências bem como apontar alguns caminhos para 0 fortalecimento de pesquisas, projetos e novas políticas públicas.

\section{DESENVOLVIMENTO}

A partir de meados do século $\mathrm{XX}$, a aproximação do design junto ao artesanato brasileiro, em diferentes contextos sociais, foi sendo promovida de certa forma pelo envolvimento de diversos "designers" entre os quais Lina Bo Bardi, por meio de suas importantes exposições; por Aloísio Magalhães, via pesquisas e registros promovidos pelo Centro Nacional de Referência Cultural (CNRC); e, posteriormente, por Janete Costa, pelas intervenções diretas realizadas nos artefatos artesanais, deslocando-os de seus locais de origem popular para dentro de ambientes residenciais e comerciais urbanos. Nesse momento, o design, ao entrar no mundo do artesanato, propiciou o surgimento de um novo cenário, valorizando a tradição através de um olhar contemporâneo. 
Com o incentivo de politicas públicas de fomento no fim dos anos 1990 os projetos de design junto ao artesanato começaram a se intensificar. Nesses novos cenários o surgimento dessas novas formas de interação entre o design e o artesanato foram ganhando forma.

Os núcleos de extensão passam a atuar junto a grupos de produção artesanal vinculados a projetos acadêmicos. A iniciativa do Laboratório O Imaginário estimula uma nova forma de atuação aproximando estudantes do processo de produção artesanal. O modelo desenvolvido pelo Imaginário foi construído a partir de algumas experiências durante as primeiras ações em 2001. Com a proposta de um modelo sistêmico e multidisciplinar, seus cinco eixos norteadores (gestão, design, comunicação, mercado e produção). Nesse modelo sistêmico os eixos podem ser aplicados isoladamente e/ou concomitantemente dependendo das necessidades diagnosticadas para cada projeto e grupo produtivo. Em suas experiências vivenciadas atuaram em ações de curta duração (4 - 6 meses) e longas (1 - 2 anos). Ao longo dos anos, observa-se que os projetos duradouros se apresentam mais eficientes, pois permitem acompanhar e avaliar os resultados propostos em cada eixo de atuação, visto que a proposta d'O Imaginário não está somente no desenvolvimento de novos produtos, mas também na valorização do artesão e de toda a comunidade envolvida estimulando o fortalecimento da cultura local.

Quando as ações acontecem em longo prazo, como no caso de duas comunidades que O Imaginário atende desde 2003 (Cerâmica do Cabo de Santo Agostinho e Comunidade de Ponta de Pedra), observa-se que é possível promover a autonomia e autogestão dos grupos, contribuindo com uma efetiva transformação social. Assim, as ações de curta duração acabam sendo focadas mais no desenvolvimento de novos produtos e no processo de produção, que também podem oferecer um resultado interessante, mas de maneira pontual e imediatista.

Essas constatações advêm das experiências práticas, de diversos processos de avaliação e do desenvolvimento de pesquisas. A importância da trajetória da atuação do Laboratório (14 anos) faz com que seus projetos e suas pesquisas sejam reconhecidos nacionalmente, reafirmando que a parceria entre design e artesanato se consolida de forma colaborativa e enriquecedora tanto para os designers quanto para os artesãos.

Em relação à comercialização e divulgação, o Laboratório não comercializa os produtos desenvolvidos pelas comunidades atendidas, mas acompanha e orienta o processo de produção auxiliando diretamente a divulgação das ações por meio das redes sociais. Também realiza consultorias para apresentação dos produtos em feiras e exposições estimulando a inserção do produto artesanal no mercado.

A importância do conceito sustentabilidade nesse modelo se destaca desde o início das ações e é reafirmada pelo contato com comunidades tradicionais e não tradicionais. $\mathrm{O}$ uso de materiais reciclados e/ou locais contempla aspectos ambientais que também podem ser observados nos processos de produção e desenvolvimento das ações como um todo.

De um modo geral, o modelo de atuação proposto pelo $O$ Imaginário tem um maior foco no desenvolvimento de pesquisa para a área acadêmica do design e também no desenvolvimento local e na transformação social, promovendo e acompanhando as comunidades por meio de atividades (projetos) de maior duração, unindo tradição e inovação por meio de ações de design. 
Com um histórico mais recente de atuação, mas não menos importante o Laboratório de Design Solidário - LabSol apresenta um outro modelo de atuação no qual suas etapas são realizadas sequencialmente em três momentos bem definidos: Visita/Troca de Saberes (Workshop); Experimentação e Pesquisa; e Pós-Visita. Essa maneira de atuar junto a grupos de produção artesanal vem sendo aplicada desde os primeiros anos de atuação do Laboratório (2007). De forma linear esse modelo sempre é aplicado sequencialmente para todos os projetos. Observa-se que o envolvimento com os estudantes de graduação, de certa forma, foi o que modelou a estrutura de atuação do Labsol. As três etapas são aplicadas sequencialmente e o tempo de duração para desenvolvimento das ações é de aproximadamente seis meses podendo se estender de acordo com a necessidade dos grupos e localização. A rotatividade da equipe, composta quase que exclusivamente por estudantes, faz com que os projetos sejam mais pontuais e de certa forma acompanhem o calendário acadêmico da Universidade para que os estudantes possam vivenciar e experimentar todos os processos do modelo de atuação.

Nesse sentido, acredita-se que esse modelo contribui para o ensino do design. Visto que as atividades de extensão aproximam e estimulam o desenvolvimento de projetos reais que envolvem além de produtos para fins industriais tradicionais, concepção de produtos e relacionamento entre designers e artesãos. Essa troca de experiência amplia as possibilidades de atuação do designer desde a sua formação.

No modelo proposto pelo Labsol, assim como no Laboratório O Imaginário os atuantes não se responsabilizam pela comercialização dos produtos artesanais desenvolvidos. $O$ Laboratório auxilia e promove feiras e exposições esporádicas como forma de divulgação do trabalho realizado pela parceria LabSol e grupo produtivo, assim como mantém suas ações e os resultados atualizados nas redes sociais.

O conceito de ecodesign apresentado como um dos tripés para os projetos do Labsol está diretamente relacionado à busca em trazer para o universo do design os princípios de ecoeficiência atentando sobre impactos ambientais e utilização consciente dos recursos naturais. A sustentabilidade aborda questões ambientais, sociais e econômicas de maneira mais abrangente em diferentes áreas do conhecimento e se firma como base tanto para o ecodesign como para as propostas de economia solidária.

Compartilhando desses princípios, o LabSol busca identificar e atuar com grupos de produção artesanal que já participam, ou podem vir a participar, de ações de economia solidária como forma de fortalecimento e reconhecimento do trabalho artesanal, além de estimular novas formas de comercialização e valorização do trabalho, sua origem e processo de produção, que envolve o desenvolvimento do produto artesanal.

Para o desenvolvimento de ações junto a grupos de produção artesanal, os núcleos de extensão realizam suas atividades através de demandas diretas, que chegam através de órgãos de fomento ou via associações (ONGs, OSCIPs), e/ou submetem projetos a diferentes editais, incluindo projetos de pesquisa financiados pela própria instituição de ensino ou por fundações e agências de incentivo à pesquisa. Devido à sua experiência de atuação, desde o ano de 2001, o Laboratório O Imaginário opta por desenvolver projetos mais autônomos, mantendo como prática submeter projetos a editais vinculados a empresas públicas e privadas e instituições de pesquisa. Dessa maneira é possível ter um controle maior de todos os procedimentos para a 
realização da ação. A partir dos projetos aprovados em editais, O Imaginário consegue manter um vínculo mais duradouro com grupos de artesãos já consolidados (que trabalham com artesanato de forma organizada) possibilitando o desenvolvimento de projetos que, além da melhoria do produto artesanal, visam promover novos processos e experimentos com foco em pesquisa, assim como apresentam novas perspectivas de produção e valorização do trabalho artesanal (considerando aqui valores culturais, sociais e ambientais).

Diferentemente, o LabSol opta por desenvolver ações a partir de demandas que chegam ao Laboratório por intermédio de associações (de artesãos ou através de outras ONGs), ou por meio de estudantes e professores. O Laboratório executa ações de curto prazo e não aprofunda os projetos junto a grupos já trabalhados. Essa dinâmica de atuação pode estar associada ao seu próprio perfil organizacional, visto que, de certa forma, quem dita a dinâmica desses projetos são os próprios estudantes de graduação, que permanecem aproximadamente um ano no Laboratório (equipe rotativa).

Os procedimentos abordados em cada modelo de atuação reforçam as singularidades com que cada Laboratório se estruturou para executar e promover ações de design junto ao artesanato priorizando atividades de ensino, pesquisa e extensão.

Também é interessante destacar que o fato de os Laboratórios estarem inseridos em universidades públicas proporciona uma estabilidade financeira e de estrutura física permitindo experimentos, pesquisas e desenvolvimento de metodologias, produtos, técnicas e materiais que fortalecem ainda mais a relação entre o design e o artesanato. Para Bonsiepe (2011), a pesquisa em design consiste em poder fornecer subsídios que melhorem a prática projetual. Assim, as experiências construídas a partir do aprendizado e da troca de conhecimentos junto a grupos produtivos podem estimular a capacidade do designer em buscar novas soluções projetuais (envolvendo grupos de produção artesanal com diferentes propostas de inclusão social e econômica), contribuindo com alternativas inovadoras que beneficiem a sociedade como um todo.

As Associações e ONGs, representantes do terceiro setor, passaram a atuar no país atendendo novas demandas sociais e ambientais. Orientado por essas premissas o Centro Pernambucano de Design - CPD - após um ano de incubação junto ao SEBRAEPE se consolidou em 2005 com apoio de instituições estaduais para desenvolver ações de design com ênfase no artesanato como forma de transformação social atendendo demandas locais e estaduais.

Durante seu período de incubação, testou alguns procedimentos, criou algumas estratégias e seus procedimentos foram sistematizados em sete etapas: diagnóstico; gestão de grupo; gestão do processo produtivo; gestão do produto; gestão do mercado; avaliação final dos resultados; e divulgação e promoção. Este modelo se apresenta de forma linear, podendo ser aplicado integralmente (sequencialmente) ou em etapas isoladas, dependendo da solicitação da demanda.

A relação das trajetórias das ações desenvolvidas pelo Centro está diretamente relacionada com as políticas de incentivo ao artesanato e agentes financiadores. O Centro realiza muitas ações em diferentes grupos produtivos, para isso conta com consultores externos que executam ações pontuais como prestadores de serviço (pessoa física ou jurídica). De certa forma, são esses consultores que 
aplicam o modelo de atuação do Centro durante as ações junto a grupos de produção artesanal. Já a equipe interna gerencia, coordena e busca novas demandas de projetos.

Assim como os Núcleos de Extensão o CPD não pratica a comercialização de produtos artesanais desenvolvido pelos grupos, mas estimula essa prática em seu modelo de atuação e promove orientação sobre a gestão de mercado.

Observa-se que o Centro Pernambuco de Design desenvolve importantes projetos que fortalecem a relação entre o design e o artesanato na região Nordeste do país e também a relação do design com diversos segmentos de mercado. Por meio da contratação de consultores, o Centro também fomenta a atuação de designers locais junto ao artesanato, incentivando novos caminhos e possibilitando a interação dos mesmos com diferentes realidades.

Por também atuar em outras especialidades do design (gráfico, serviço) alia diferentes propostas junto a grupos de produção artesanal, micro, pequenas e médias empresas e também orienta empreendedores individuais estimulando o mercado local. Começa, recentemente, a introduzir algumas ações vinculadas à economia criativa. Acredita-se que, mesmo tendo liberdade para atuar e propor novos projetos, a associação ainda se mantém restrita e pouco ousada na busca de novas parcerias e, consequentemente, novas oportunidades de ampliar suas ações junto ao artesanato.

Com um histórico também de incubação o Design Possível iniciou suas atividades junto ao artesanato como um projeto de extensão acadêmica aproximando estudantes de design e organizações sociais da periferia de São Paulo, junto à Universidade Mackenzie. Neste período suas atividades possibilitaram o contato dos estudantes com diferentes realidades e estimularam o desenvolvimento de projetos com foco no produto artesanal e também na inclusão social por meio da geração de trabalho e renda de grupos marginalizados.

Essa experiência fez com que a estrutura do seu modelo de atuação também fosse formalizada em seis módulos (formação de grupo, consolidação da técnica, dinâmica de mercado, desenvolvimento de produtos, produção e comercialização e autogestão) que caracterizam um modelo de atuação linear, pois esses módulos são aplicados sequencialmente ou individualmente (um ou mais módulos dependendo da necessidade de cada grupo e do tempo de cada projeto). O tempo considerado ideal para execução de todas as etapas é de um ano (12 meses), aproximadamente dois meses por etapa, assim a organização opta por projetos de curta e média duração, nos quais pelo menos um ou dois módulos são executados.

Diferentemente dos Núcleos de Extensão, do CPD, o Design Possível optou pela comercialização dos produtos artesanais devido a necessidade dos grupos de artesãos em conquistar novos clientes. Com tipologia de artesanato urbano, os produtos artesanais produzidos por grupos da periferia de São Paulo são confeccionados a partir do reaproveitamento de materiais, como resíduos industriais.

O Design Possível ainda mantém contato com os grupos, principalmente para auxiliar, orientar e incentivar a comercialização dos produtos. Promovendo e fortalecendo uma constante formação de redes de contato entre consumidores, associações, designers e empresas. Desse modo, a ONG consegue desenvolver diferentes projetos com diversos grupos, mas, de certa forma, acompanha os antigos projetos, o que lhes permite avaliar os resultados das atividades propostas.

Com o foco em públicos semelhantes (grupos de artesãos), o Design Possível e o Centro Pernambucano de Design, localizados em dois estados diferentes, foram se 
adaptando aos cenários locais, se estruturando e criando seus próprios modelos de atuação.

Devido à formação estrutural do Centro, a partir de diferentes sócios fundadores (pessoas jurídicas), a garantia de demandas de trabalho é mais estável; no entanto, isso acaba engessando o modelo de atuação e acomodando a equipe de trabalho, visto que os projetos, muitas vezes, propõem ações similares. Em contrapartida, o Design Possível apresenta mais autonomia na formatação e no direcionamento das ações, pois está sempre buscando novos parceiros, pois não tem um agente de fomento que garanta a demanda constante de projetos.

Para as ações individuais o processo de atuação junto a grupos de produção artesanal é extremamente particular, são atividades realizadas, em sua maioria, por profissionais da área de design e/ou arquitetura de forma autônoma. Reconhecidos por meio da identidade singular dos seus trabalhos esses atores desenvolvem modelos próprios de atuação.

O modelo de atuação proposto pela designer Paula Dib valoriza o processo artesanal como um todo. Propondo um realinhamento de soluções, ela inicia as ações com um diagnóstico local e, a partir desse primeiro passo, as outras atividades começam a ser pensadas e executadas. Denominado como método de "alfaiataria", não existem etapas pré-definidas e o tempo de cada ação dura em média de um a dois anos (12 a 24 meses). Esse modelo foi sendo construído e denominado por ela ao longo de diferentes experiências em diversos projetos.

Observa-se que seu trabalho e sua forma de atuação ganharam destaque por promover ações do design que buscam valorizar culturalmente os saberes e as técnicas do fazer manual. Nesse modelo, ela auxilia, orienta e também acompanha os artesãos no processo de desenvolvimento e produção dos produtos, incentivando também o empreendedorismo e a autonomia dos grupos. Ela apoia a participação em feiras de comercialização, mas não participa da comercialização direta dos produtos.

Retomando práticas ecológicas que originalmente eram empregadas por artesãos mais tradicionais, como por exemplo, em comunidades indígenas, ela exercita o caminho de volta tentando repassar para os artesãos a ressignificação dos processos que se perderam ou foram substituídos ao longo do tempo. Relaciona-se aqui o tema da globalização e da industrialização acelerada por que o Brasil passou e de toda a pulverização de produtos industriais com padrões internacionais que de certa forma anulou, negou e inferiorizou a cultura nacional e suas manifestações populares vinculadas à produção artesanal. Nesse sentido, sua atuação em projetos de design e artesanato é especialmente voltada a um resgate cultural de saberes manuais que abrangem o design a questões sociais, ambientais e econômicas.

O trabalho do designer Sérgio Matos também tem grande foco no resgate cultural e nas técnicas tradicionais, influenciado pelo artesanato e pela cultura popular da Paraíba na região Nordeste do país, ele busca na produção artesanal a inspiração para seus projetos de design (móveis e objetos de decoração) e também para colaborar e orientar no desenvolvimento de produtos junto a grupos de produção artesanal.

Sua atuação recente, desde 2012, junto a grupos produtivos está estruturada em 11 etapas (pesquisa local; levantamento de materiais; levantamento de temas para o conceito; geração de ideias; aprimoramento das ideias; testes; protótipos; peça piloto; produto final; divulgação; e lançamento). Com o foco no resultado do 
desenvolvimento de novos produtos, ele explica que temas como empreendedorismo, gestão do grupo e vendas, por exemplo, são realizados através de outras consultorias e não fazem parte do seu modelo.

Essa é uma diferença do seu modelo para os demais, ele foca suas ações na prática e técnica artesanal juntamente com o uso de materiais locais. A temática sobre sustentabilidade é referenciada em seu trabalho principalmente em relação às propostas de aproveitamento de materiais, contribuindo com os artesãos e a paisagem local. Sua atuação junto a grupos produtivos também provoca um impacto positivo em relação ao aumento de geração de renda para os artesãos, pois a comercialização de novos produtos artesanais ganha destaque por terem sido criados com sua participação.

Quanto à comercialização, a maneira com que Sérgio Matos se envolve com o processo de produção e acompanhamento de vendas dos produtos gerados durante as oficinas com grupos produtivos está diretamente relacionada com sua rede de contatos. Considerando o seu reconhecimento profissional nacional, ele incentiva e auxilia a participação dos grupos em diferentes feiras e exposições de design e/ou artesanato. Dessa maneira, ele apoia a inserção dos produtos artesanais no mercado e consequentemente a valorização do artesanato e o reconhecimento da relação entre o design e o artesanato.

$\mathrm{Na}$ atuação autônoma de Paula Dib e de Sérgio J. Matos, em projetos que aproximam o design ao artesanato, é possível observar que a história de vida desses dois profissionais e suas referências e experiências pessoais influenciaram diretamente nas suas escolhas de atuação junto ao artesanato.

Paula Dib desenvolve ações tanto como consultora, prestando serviços para empresas e associações, quanto como propositora de projetos através de editais de fomento. Já Sergio Matos atua com grupos produtivos através de prestação de serviço (consultoria) ou através de projetos pessoais, associando o processo de produção de seus produtos junto a artesãos da região da Paraíba. Os dois designers olham para a cultura brasileira e buscam nas raízes de suas origens a contribuição para os seus trabalhos.

A análise sobre esses dois designers revela que é possível aproximar o design da produção artesanal tanto como proposta de projetos autorais (uma das vertentes do trabalho de Sérgio Matos) que transforma técnicas, matérias e saberes artesanais em novos produtos com características formais e conceituais contemporâneas, quanto no desenvolvimento coletivo junto a grupos de artesãos (proposta enfatizada no trabalho de Paula Dib) que, além do objeto artesanal, envolve conscientemente e ativamente a participação dos artesãos em todos os processos de criação, gestão, produção, distribuição e comercialização dos produtos artesanais.

\section{CONSIDERAÇÕES E REFLEXÕES}

O paralelo criado nesta pesquisa entre modelos que desenvolvem atividades de design em grupos de produção artesanal tanto no estado de São Paulo (Sudeste) quanto nos estados de Pernambuco e Paraíba (Nordeste) permite considerar que a relevância da atuação proposta por cada caso ultrapassa fronteiras estaduais e adquire uma importância em território nacional, visto que a maioria das ações é reconhecida nacionalmente. 
A contribuição cultural, social, econômica e ambiental que esses casos buscam atribuir ao artesanato e, consequentemente, à área do design, enriquece e incentiva novas políticas de fomento ao artesanato, que realimentam o design e estimulam o desenvolvimento de mais ações com esse perfil. Isso comprova que, cada vez mais, o artesanato e o design vêm mutuamente se fortalecendo como atividades colaborativas.

A partir do contato direto com os modelos estudados, por meio de entrevistas, visitas e observação e análise, pode-se perceber que não existe uma única maneira, nem o melhor modelo, para se atuar com grupos produtivos. O que existe é a vontade de que novas relações sejam estimuladas e possam fortalecer ainda mais o contato entre o design e o artesanato brasileiro.

Com intuito de apontar alguns possíveis caminhos para o maior fortalecimento do design e do artesanato brasileiro, é importante ressaltar que os núcleos de extensão colaboram com ações de caráter mais experimental, de curto, médio e longo prazo, fomentando pesquisas que fortalecem a atuação do design junto ao artesanato em âmbito acadêmico, mas que também podem colaborar com os demais modelos de atuação (associações e ações individuais).

As associações apresentam de certa forma uma rigidez e um controle maior sobre seus métodos de atuação, visto que estão mais atreladas aos agentes de fomento e à necessidade de cumprirem determinadas exigências contratuais. Esse tipo de controle acaba moldando as atividades e o modelos de atuação das associações. Acredita-se que seria de extrema importância que, frequentemente, tanto as associações quanto os agentes de fomento, realizassem uma avaliação de seus modelos e práticas, para que as contribuições sociais, ambientais, políticas, culturais e econômicas alcançassem efetivos resultados em contextos contemporâneos cada vez mais dinâmicos e complexos.

Já as ações individuais executadas por profissionais autônomos apresentam características muito singulares, decorrentes de aptidão individual. Neste sentido, acredita-se que o estimulo à atuação do designer junto à núcleos de produção artesanal, poderia ocorrer desde sua formação, através da sua inclusão nos projetos pedagógicos dos cursos de graduação em design, em disciplinas curriculares obrigatórias e/ou optativas, que abordassem a atuação dos futuros designers em novos contextos e práticas, projetual e interrelacional, visto que atualmente esse processo, quando ocorre, se dá quase exclusivamente através de projetos de extensão.

Neste estudo, a busca pela compreensão de diferentes modelos de atuação de design junto a grupos artesanais, permitiu verificar que a relação entre o design e o artesanato e, consequentemente, entre o designer e o artesão apresenta diversas possibilidades de configuração, considerando parâmetros similares. Por exemplo, as questões sobre meio ambiente são consideradas em todos os modelos principalmente através do uso mais consciente de materiais e processos. Os aspectos sociais, envolvendo processos relacionados ao desenvolvimento local, são destacados nas ações de longa duração, pois permitem uma melhor avaliação sobre todas as atividades executadas junto aos grupos. Os casos que, de certa forma, "incubam" (acompanham) grupos de produção artesanal por mais tempo conseguem apresentar resultados mais consolidados. Em contrapartida, as ações mais pontuais perdem sua continuidade com o passar do tempo, embora tenham um "frescor" criativo interessante. 
Como proposta de aprofundamento para este estudo, é possível realizar investigação em algumas comunidades e grupos de artesãos que já foram orientados por ações de design promovidas por esses mesmos seis casos estudados, dessa maneira seria possível avaliar os impactos e resultados alcançados. Também seria interessante propor que uma mesma comunidade experimentasse diferentes modelos e observar, ao logo do tempo, como os resultados se apresentariam. Por fim, é possível pensar também em uma investigação mais pontual e multicolaborativa, estimulando a partir de uma mescla de modelos, ações e reflexões sobre diferentes impactos causados a partir de uma imersão de atuação colaborativa.

\section{REFERÊNCIAS}

ABBONIZIO, Marco Aurélio. Aproximação teórica das intervenções do design no artesanato com os princípios pedagógicos de Paulo Freire: caminhos para uma prática emancipatória. 2009. Dissertação (mestrado) - Universidade Federal do Paraná, Curso de Pós-Graduação em Design.

BARDI, Lina Bo. Tempos de Grossura: o design do Impasse. São Paulo: Instituto Lina Bo e P. M. Bardi, 1994.

BONSIEPE, Gui. Design, Cultura e Sociedade. São Paulo: Blucher, 2011.

BORGES, Adélia. Design e Artesanato: o caminho brasileiro. São Paulo: Ed. Terceiro Nome, 2012.

CARDOSO, Rafael. Introdução à história do design. São Paulo: Ed. Blücher, 2004.

CHITI, Jorge. Artesania, Folklore y Arte Popular. Buenos Aires: EdicionesCondorhuasi, 2003.

MAGALHÃES, Aloísio. E Triunfo?: a questão dos bens culturais no Brasil. Rio de Janeiro: Nova Fronteira; [Brasília]: Fundação Nacional Pró-Memória, 1985.

ONO, Maristela Mitsuko. Design e Cultura: sintonia essencial. Curitiba: Edição da Autora, 2006.

SEBRAE. Termo de Referência. Programa Sebrae de Artesanato. Brasília: Sebrae, 2010. Disponível em: <http://sebrae.com.br>Acesso em 25/04/2012.

SILVA, Heliana. Por uma teorização das organizações de produção artesanal: habilidades produtivas nos caminhos singulares do Rio de Janeiro. Tese de Doutorado em Administração - Faculdades Getúlio Vargas, 2006.

YIN, Robert K. Estudo de Caso: planejamento e métodos. Porto Alegre: Bookman, 2001. 